\title{
Piloted Evaluation of the H-Mode, a Variable Autonomy Control System, in Motion-Based Simulation
}

\author{
Kenneth H. Goodrich ${ }^{1}$ and Paul C. Schutte ${ }^{2}$ \\ NASA Langley Research Center, Hampton, VA, 23681 \\ Ralph A. Williams ${ }^{3}$ \\ Analytical Mechanics Associates, Hampton, VA, 23666
}

\begin{abstract}
As aircraft become able to autonomously respond to a range of situations with performance surpassing human operators, we are compelled to look for new methods that help understand their use and guide the design of new, more effective forms of automation and interaction. The "H-mode" is one such method and is based on the metaphor of a welltrained horse. The concept allows the pilot to manage a broad range of control automation functionality, from augmented manual control to FMS-like coupling and automation initiated actions, using a common interface system and easily learned set of interaction skills. The interface leverages familiar manual control inceptors (e.g., the control stick) and flight displays through the addition of contextually dependent haptic-multimodal elements. The concept is relevant to manned and remotely piloted vehicles. This paper provides an overview of the H-mode concept followed by a presentation of the results from a recent evaluation conducted in a motion-based simulator. The evaluation focused on assessing the overall usability and flying qualities of the concept with an emphasis on the effects of turbulence and cockpit motion. Because the $\mathrm{H}$-mode results in interactions between traditional flying qualities and management of higher-level flight path automation, these effects are of particular interest. The results indicate that the concept may provide a useful complement or replacement to conventional interfaces, and retains this usefulness in the presence of turbulence and motion.
\end{abstract}

\section{Introduction}

$\mathrm{M}$ otivated by improved performance, efficiency, and safety, highly automated aircraft are commonplace in all forms of aviation. Further, the continuing information technology revolution enables development of vehicles with the functional intelligence to autonomously respond to a wide variety of internal and external, dynamic situation elements with performance often exceeding the human crewmembers. At the same time, a large body of experience with highly automated aircraft highlights several fundamental challenges that limit the effectiveness of current systems [1-4]. Briefly summarized, these challenges include heavy reliance on memorized action sequences, workload spikes caused by reformulation of operational tasks into subtasks understood by the automation, stupefying workload lulls, complacency, skill attrition, inflexible automation support, and sudden, unexpected changes in automation behavior. Furthermore, unless the basic form of human-machine interaction is improved, the adverse effects of these challenges are likely to be more pronounced as automation becomes both more capable and used by potentially less experienced and/or supervised operators (e.g., single, private pilots or remote operators versus a multi-pilot, commercial flight crew). While eliminating the possibility of human intervention or limiting it severely (e.g., a wave-off button) may be seen as solutions, this approach is not without numerous and as yet unsolved issues for complex systems and environments such as those typical of aviation [5,6]. The development of artificial systems with broad, human-like "common sense" and creative problem solving skills remains a "grand goal" as described by leading researchers such as Minsky [7]. From a practical perspective, systems that do not support flexible human interventions are likely to remain more expensive and less robust than systems that do for some time to come.

\footnotetext{
${ }^{1}$ Aerospace Technologist, Dynamic Systems and Guidance Branch, Mail Stop 308, AIAA Senior Member.

${ }^{2}$ Aerospace Technologist, Crew Systems and Aviation Operations Branch, Mail Stop 152.

${ }^{3}$ Senior Analyst, Dynamic Systems and Guidance Branch, Mail Stop 308.
} 
Given this situation, we are compelled to develop new forms of automation and interaction that fully exploit emerging automation technologies and support flexible, efficient human and machine cooperation. The balance of this paper outlines one such concept and presents the results of a piloted simulation study of its usability.

\section{Overview of the H-metaphor}

As described in detail in references 8-11 and summarized here, for near-term (i.e., tactical) management of a highly automated aircraft the relative roles, responsibilities and interactions between a well-trained horse and rider may provide a potentially useful exemplar and design metaphor. In the horse metaphor or "H-metaphor", the machine acts as an autonomous but obedient animal. It understands simple commands and is highly depended on for its skill and procedural-based behaviors but not for long-term, knowledge-based behaviors. As described in reference 10, strategic decision making is better served by other automation and interaction concepts. Our intention is that $\mathrm{H}$-metaphor derived automation would be part of an integrated system with other elements supporting longterm decision aiding.

The H-metaphor has several dimensions of particular relevance to aircraft automation and human interaction. As an autonomous agent, a horse is extremely adept at locomotion in various terrains and conditions including maneuvering in close proximity to dynamic elements such as other animals. A horse avoids immediate hazards while, within its limited understanding, supporting the rider's objectives. This independent intelligence allows the rider to direct the horse's actions over a range of autonomy levels using a simple but flexible set of interaction skills. At one extreme, the rider can exercise "tight-rein" control providing nearly direct control over the horse's instantaneous actions (e.g., fig. 1). At the other extreme, the horse performs more goal-oriented, "loose-rein" behaviors such as following a trail or station keeping relative to a moving target (e.g., fig. 2). During loose-rein behaviors, a rider is freed to divert much of their attention elsewhere such as throwing a lasso or simply enjoying the scenery. In many situations this variable autonomy creates a fluid partnership between horse and rider in which control is truly shared in parallel rather than the "exclusive or" between an operator and conventional automation.

It should be recognized that even in tight-rein the rider is only directly controlling the external behaviors of the horse. Direct management of internal functions is not something the rider is responsible for. Of course, a good rider must have an understanding of the practical constraints imposed by these functions and depending on the temperament of the horse, the rider will receive increasingly salient feedback, and ultimately resistance, as limits are approached.

A horse and rider interact through multimodal (e.g., visual, auditory, touch) communication underpinned by a strong, bi-directional haptic component. The haptic senses (e.g., proprioception and cutaneous touch) are unique in that they both sense and effect the external environment. This bi-directionality naturally supports two-way communication. Furthermore, as a vector quantity having direction and magnitude, force provides a natural means of communicating concepts such as the direction and urgency of a desired maneuver. These properties enable robust and rapid, bi-directional communication and negotiation between horse and rider. For example, considering the case of a horse cart in which the horse and rider (or driver) do not have direct bodily contact, the reins still form a bi-directional link with both agents able to transmit and receive information. According to the German National Equestrian Federation [13], the driver performs turns by yielding the outside rein with a twist of the hand(s), not pulling the inside one. Further, there should always be a "soft, steady, elastic connection" between the driver's hand and horse's mouth, where "the

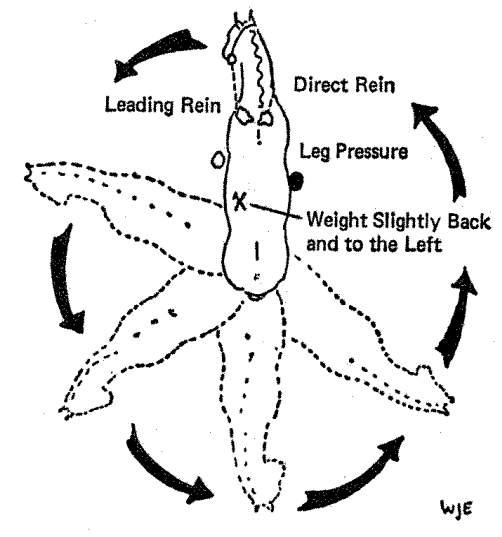

Figure 1. Example of tight rein control to perform a spin [12]

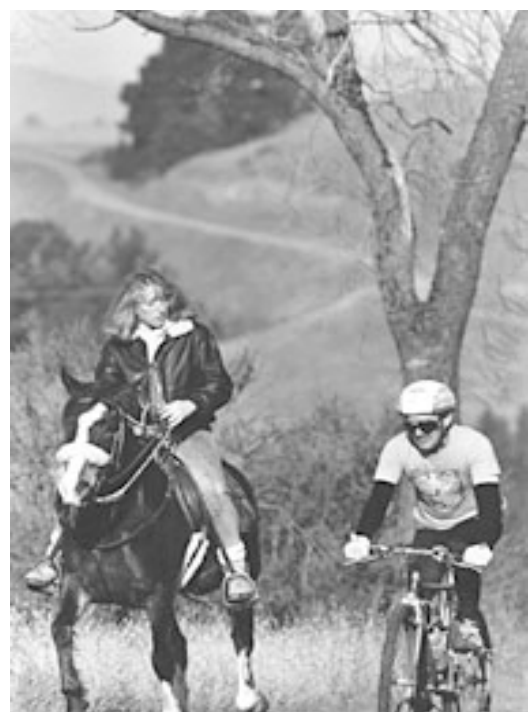

Figure 2. Loose rein control. Note the gaze of the rider versus cyclist 
horse seeks the contact and the driver provides it". If the horse wants to change direction, perhaps to avoid a rut, it leads with a turn of its head. The rider feels a change in rein tension and can accept or reject the action by relaxing or increasing the tension. In addition, discrete communication elements such as an agitated jerk (possibly accompanied with an auditory snort and visual tail flick) are often superimposed on the more continuous signals for added emphasis. Furthermore, from a lack of any tension, the horse can infer that the driver is relatively disengaged and adjust its expectations accordingly. If a horse is uncertain as to how to proceed, it typically tries to engage the rider before acting independently.

Although a horse's situational understanding is very different than a human's, there is sufficient overlap that most interactions are aided through contextual understanding and simple intent inferencing. For example, directing a horse to pass through an open gate does not require precise steering like a car. Rather, the horse infers the action from the direction of travel toward the gate and will make the necessary corrections without explicit commands. At the same time, horses rarely know the high-level goals or mission of their riders (except in TV and movies) and the human must give simple, frequent commands such as go left, catch-up, jump, etc. These regular interactions help keep the rider aware of the immediate situation with relatively low effort and may help mitigate the sort of potentially hazardous detachment that can result from fully automated execution of long pre-programmed action sequences (e.g., entire flight plans) without any required human involvement.

Table 1. Median time for issuance of commands (ref 14)

\begin{tabular}{|l|l|l|}
\hline Interface & $\begin{array}{l}\text { Median Time } \\
\text { (secs.) }\end{array}$ & Std. Dev. \\
\hline Attitude joystick & 1.04 & 0.54 \\
\hline Physical icon & 1.24 & 0.41 \\
\hline Attitude TrackPoint TM & 1.31 & 0.46 \\
\hline Direct manipulation, mouse & 1.43 & .53 \\
\hline Direct manipulation, stylus & 1.80 & 0.68 \\
\hline Direct manipulation, trackpad & 2.19 & 0.98 \\
\hline Voice recognition & 2.37 & 1.11 \\
\hline Numerical parameter entry & 2.73 & 1.17 \\
\hline
\end{tabular}
for simple, spatially referenced commands such "go up", "turn right", etc. Further, the risk of potential miscommunications (e.g., ... No, the other right!!) is reduced. Finally, using the haptic senses as part of a multimodal interface can off-load the other, frequently over-taxed sensory modalities (e.g., vision) and reduce cognitive processing burdens [15].

\section{The H-mode, a realization}

The $\mathrm{H}$-metaphor provides a general vision as to how an $\mathrm{H}$-inspired vehicle might interact and behave. As described in references 9, $16 \& 17$, the National Aeronautics and Space Administration (NASA) and the German Aerospace Lab (DLR) are working toward practical realizations for flight and ground vehicles respectively. These developing realizations are known as the "H-mode" and are intended to be compatible with current technologies, such as commercially available haptic interface hardware (e.g., active, force-feedback side-sticks), while providing a framework that logically accommodates and leverages emerging and future technologies such as autonomous "sense and avoid" and reconfigurable control technologies. A goal shared by NASA and DLR is the creation of specific, yet malleable automation design and user interaction guidelines that can be applied across a wide range of "intelligent" vehicles including ground vehicles, aircraft, and spacecraft. The core knowledge and skills of users and designers should be transferable across vehicle classes in a consistent and meaningful form.

The research described in this paper represents an exploration of some of the fundamental concepts and potential issues of NASA's aircraft implementation described in reference 9. As noted in reference 9, the H-mode creates interactions between the aircraft's basic flying qualities and the management of higher-level, flight control automation such as intercepting and coupling to an airway. An initial, exploratory evaluation of the concept in the presence of operational representative, transient aircraft motions was highly desirable to better understand the nature 
and impact of any adverse effects. Similarly, reference 9 proposes discrete, haptic signals (e.g., shaped vibrations) transmitted through the stick to help convey the status of the automation or situation. The ability to detect and discriminate such signals while exposed to realistic vehicle vibration levels was also of high interest. An evaluation exploring these two issues was recently conducted in the Visual/Motion Simulator (VMS) at NASA Langley and is the focus of the reminder of this paper. First, the functionality of the evaluated system is explained. Next, we describe how the evaluation was conducted and present the results. Finally, we conclude with a discussion of the results and expected future research.

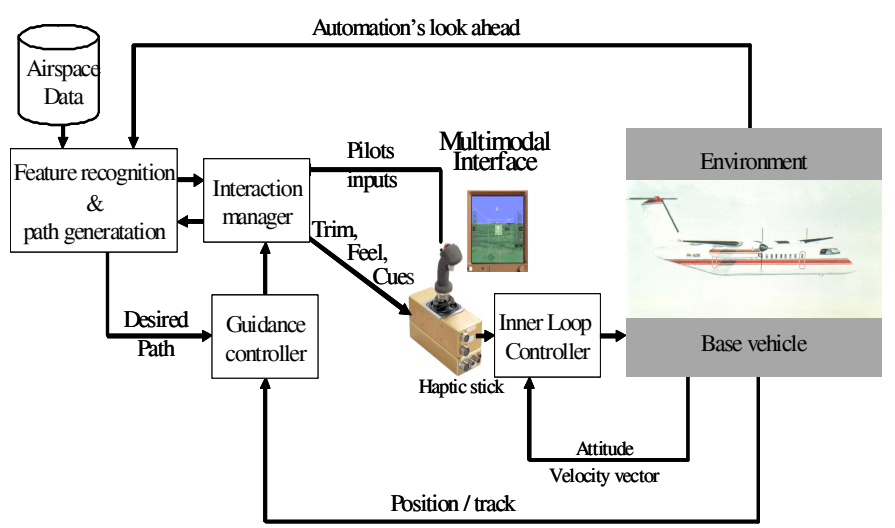

Figure 3. System block diagram

\section{Description of the Evaluated System}

A subset of the proposed H-mode functionality was evaluated in this study. The study focused on the pilot's ability to control the vehicle's instantaneous trajectory (i.e., manual control) and path based automation through a single integrated interface system. Figure 3 shows a high-level block diagram of the system and figure 4 shows the pilot interface as implemented in the VMS. The primary interface elements were an active (e.g., force-feedback) side-stick, two discrete switches on the stick, a synthetic vision system (SVS) based primary flight display, and a navigation display.

The system has two basic modes of operation, tight and loose rein (TR and LR respectively) corresponding to a low or high level of automation support. The modes will be explained in more detail below. In either mode, the airplane's instantaneous maneuver is controlled by the position of the primary inceptor (e.g., the stick) which provides the reference command acted on by the inner-loop controller. In TR, the pilot is the principal manipulator of the stick and in LR, the automation is the principal manipulator. While a principal agent is associated with each mode, the haptic stick allows both agents to make, and be aware of simultaneous inputs independent of the mode. Figure 5 illustrates how simultaneous inputs are mechanized. The interaction manager (fig. 3) manipulates the zero-force or trim position of the stick as needed for the automation to command a desired instantaneous action. If the pilot does not apply a force, the stick moves to the new neutral position and the aircraft responds accordingly. Alternatively, the pilot can apply a force to reposition the stick as they see fit. Since the stick position determines how the airplane actually maneuvers, the pilot has final authority. Clearly, this authority can be undermined if the actions of the $\mathrm{H}$-mode are abrupt or sustained against high resistance. The interaction manager situationally tailors the force-feel characteristics of the stick (e.g., force gradient, frequency, damping, and center detent) and from the pilot's perspective the automation's presence can range from subtle to forceful. The interaction manager is also sensitive to the pilot's forces and can refine or change its goals or simply defer to the pilot based on its perception of the situation. The inner-loop controller used in this study was a velocity-vector command system.

The longitudinal response type was flight-path angle rate command/flight-path hold. The lateral-response type was roll-rate command/bank angle hold. The inner-loop also maintained coordinated flight (subjects did not make rudder pedal inputs) and an auto throttle maintained a commanded speed. For simplicity, a

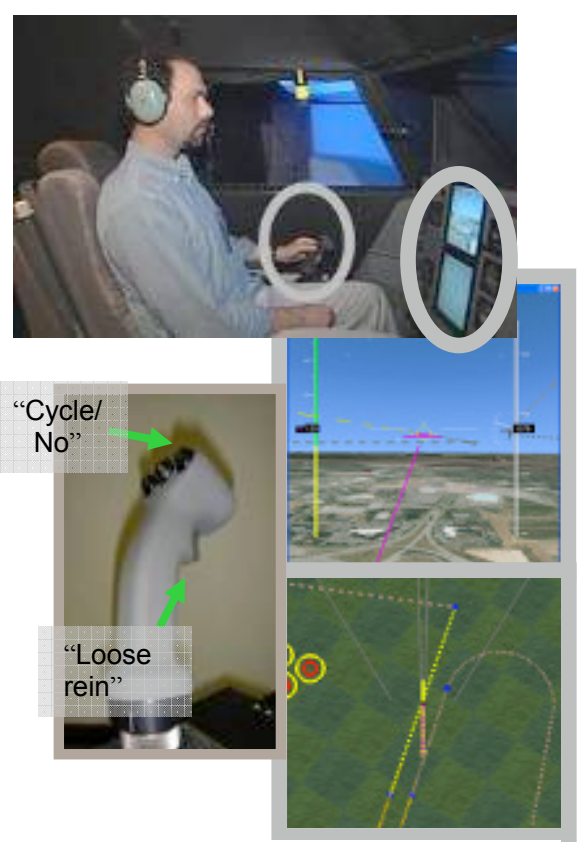

Figure 4. Pilot vehicle interface commanded airspeed of $150 \mathrm{kts}$ was used throughout the test. The 
inner-loop controller also provided envelope protection so that the aircraft would not enter an unusual flight condition. Considering the H-metaphor, the inner-loop might be compared to the subconscious functions of the central and somatic nervous systems involved in voluntary motor control, balance, and movement. Unlike a more literal interpretation of the metaphor, the current implementation requires all the automation's higher-level actions to pass through the stick, making them observable, and easily modifiable by the pilot.

TR provides the pilot with manual control without influence from the outer-loop automation unless it perceives an imminent hazard. The pilot could transition to TR at any time by either pressing the "Cycle/No" button on the stick grip (fig. 4) or sustaining a stick input that maneuvered the airplane a minimum distance away from any active LR pathway. During transitions between TR and LR, stick commands from the automation were faded in or out over a short interval $(1 \mathrm{sec})$ to ensure a smooth but positive exchange of control. In TR, the interaction manager set the feel characteristics of the stick to values providing good manual flying qualities. The interaction

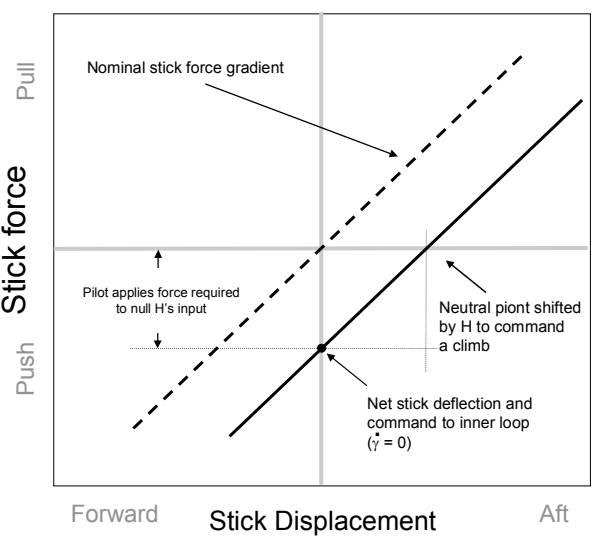

Figure 5. Net command from combined inputs manager also nominally leaves the stick's zero-force or neutral position centered, which is consistent with good manual flying qualities for rate-command/parameter-hold systems (i.e., no trim displacements are needed). Although the functionality was not formally evaluated in this study, if the automation perceived an imminent hazard (e.g., flight below the minimum safe altitude while not on an approach path), it alerted the pilot through a combination of visual and haptic cues. If the hazard was severe enough, the automation actively influenced the instantaneous maneuver to avoid the hazard. The scenarios evaluated in this study largely avoided triggering this hazard avoidance behavior and it will be the subject of future tests.

In LR, the outer-loop automation performed a sustained action or behavior designated by the pilot. The designation process is explained in detail below. In LR, the guidance controller, working through the interaction manager, continuously repositioned the neutral position of the stick as needed to perform the behavior. This repositioning was done at approximately $30 \mathrm{~Hz}$ and perceived as smooth motion. In LR, the interaction manager also stiffened the stick-force gradient, created a heavy detent around the trim position, and generated a subtle haptic "purring" sensation (e.g., a $40 \mathrm{~Hz}$ vibration with an appropriately modulated amplitude envelope). These changes made the active mode observable to the pilot simply by touching the stick. In LR, the stick displacement and interaction manager remain sensitive to forces applied by the pilot and the stiffer detent and force gradient allowed the pilot to rest their fingers on the stick to follow the automation's inputs without making inadvertent inputs or commands. In LR a magenta line, known as the "H-path" also appeared on the two visual displays and provided a visual cue as to the systems status. In addition to indicating that LR was active, the H-path provided a preview of the trajectory that the H-mode was guiding to.

In the evaluation, all the LR behaviors involved following pathways corresponding to airspace procedures or dynamically defined paths. The pilot had three basic options for designating a desired pathway as part of transitioning from TR to LR. The first option was using a "track-hold" maneuver. A track-hold maneuver simply holds the current ground track and vertical flight-path of the airplane. It was initiated by maneuvering the airplane into the desired condition and pulling the "loose-rein" trigger (fig. 4). A track-hold is analogous to using the modecontrol panel of a conventional autopilot to hold the current flight condition. With the SVS based PFD, if one wanted to generate a track to a distant feature (e.g., a landmark or waypoint) the flight-path marker (FPM) on the display could be used as a "pointing" reference. If the feature was visible inside the FPM as the trigger was pulled, the track would pass near the feature.

The second type of transition from TR to LR was a "point to program" (P2P) maneuver. P2P makes explicit use of the FPM as a targeting device. In addition to physical features such as landmarks, the displays visually depict relevant airspace procedures. These visual depictions also correspond to the automations knowledge of the surrounding airspace. When a feature the automation "recognizes" is inside the FPM and within range as indicated by a velocity-vector noodle on the navigation display, it is visually highlighted, e.g., see figure 6 . If the pilot pulls the trigger while a feature is highlighted, the appropriate operational action is programmed into the automation and activated. Figure 7 shows the situation following figure 6 shortly after the trigger is pulled. The automation has generated an intercept path (i.e., the magenta H-path) which it is coupled to and will follow to join the highlighted approach path. To perform this operation with conventional automation, pilots have to divert their attention from the primary displays and enter the intercept using an alpha-numeric keypad. 
The reader may have noticed that in figure 6, two procedures are within the targeting criteria. In such situations, the pilot used the "Cycle/No" button to cycle through the valid procedures. The number of simultaneously valid

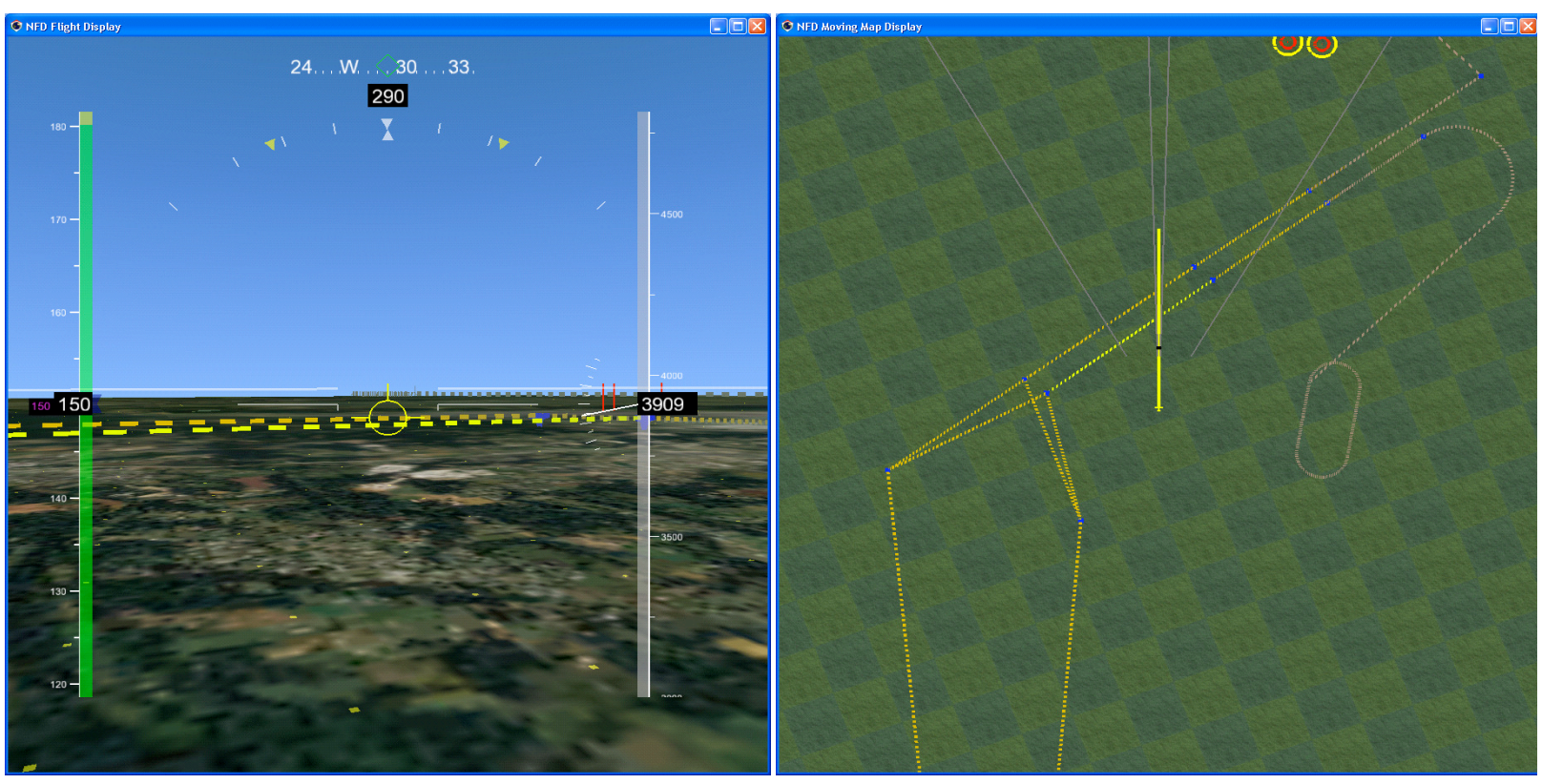

Figure 6. PFD and navigation display with highlighted procedure

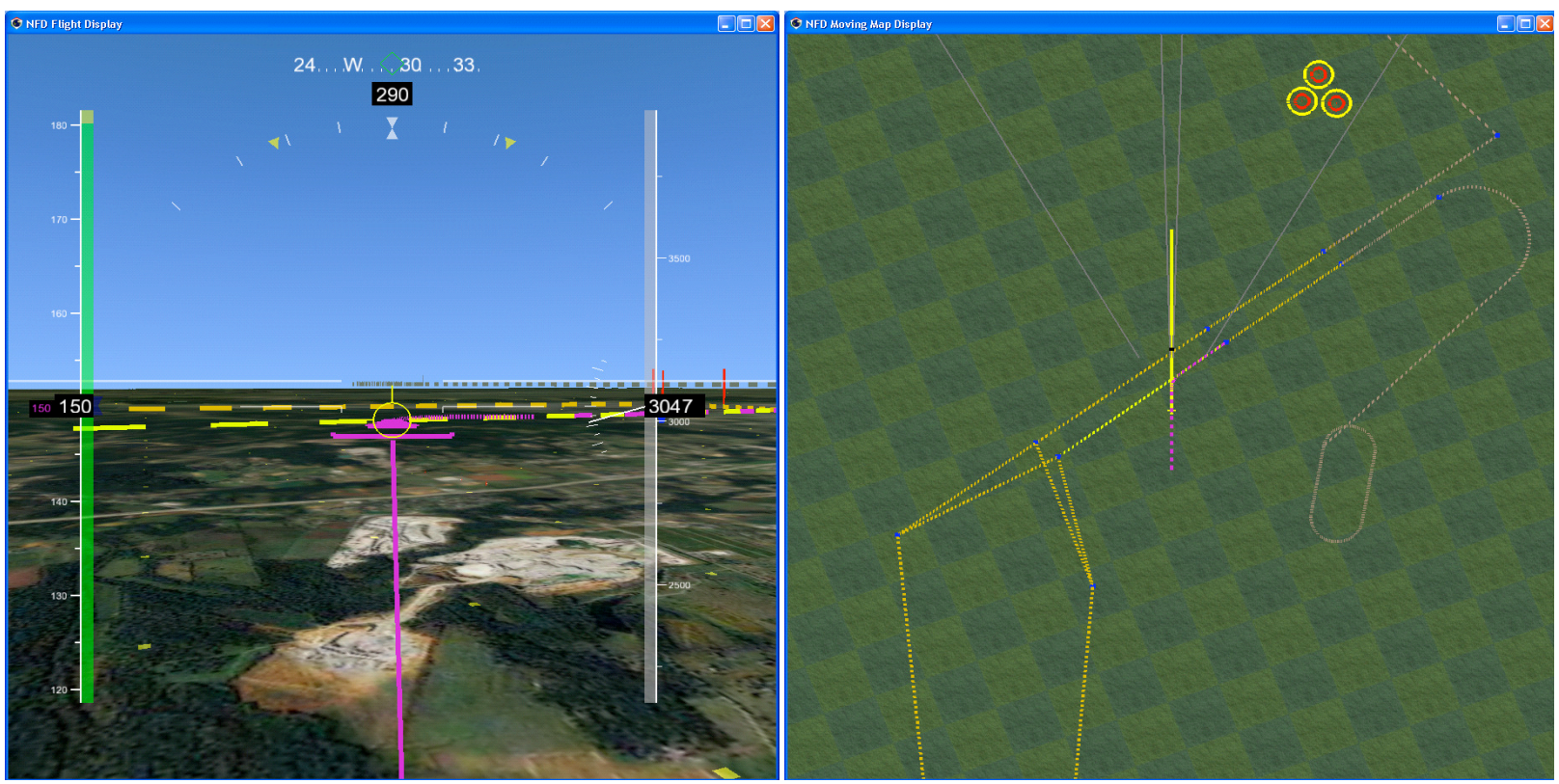

Figure 7. PFD and navigation display after P2P transition to LR

procedures is usually small and easily managed. In exceptionally complex airspace such as the Northeast corridor, additional filtering may be required to infer what features the pilot needs to see while avoiding clutter. This is an area of current research.

The radius of the FPM was 1.5 degrees relative to the external environment shown on the PFD. This radius inherently defined how precisely the pilot had to point the airplane to use the P2P function. To minimize the effects of turbulence and increase response bandwidth, the displayed FPM is based on the commanded flight path rather than the instantaneous flight path. Also, consistent with using the projection of the FPM as an aiming reference, the 


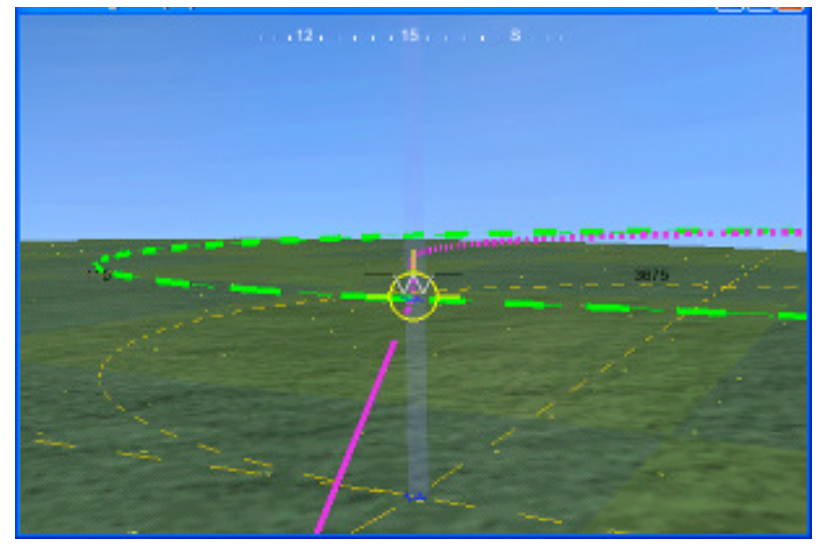

Figure 8. Waypole allows designation of altitude commanded bank angle had to be within 5 degrees of wings level for the P2P behavior to be available (i.e., the airplane had to be flying straight during the targeting). This also minimized abrupt transients during the transition from TR to LR as the initial segment to be followed was straight and aligned with the aircraft's track.

Aiming the FPM at a point in space defines both the horizontal and vertical trajectory. While this is appropriate for intercepting procedures with an explicit three-dimensional definition (e.g., approach paths), many procedures like a holding pattern may be performed at a variety of altitudes. To accommodate these situations, vertically extended waypoints known as a waypoles were used as shown in figure 8. By pointing at the desired altitude along a waypole, the associated procedure is generated at that altitude. To simplify the altitude selection process, the feature recognition automation used operationally appropriate increments such as offering holding patterns only at cardinal altitudes (e.g., 1000' increments) along the extent of a waypole.

The third way of transitioning from TR to LR was using a "proximity join". To proximity join, the pilot maneuvered the airplane into proximity and alignment with a desired airspace procedure using the visual displays. When the airplane was positioned appropriately, the feature recognition automation highlighted the segment and cycling the trigger completed the transition to LR. From the pilot's perspective, a proximity join and close-range P2P appear similar and he may not know, or have need to know, which method the automation used to join a path. The path recognition criteria used in this study was a lateral offset less than 72 feet; a vertical offset less than 16 feet; and a heading misalignment less than 20 degrees. To help smooth the joining process, it was found to be advantageous to calculate these offsets using a projected position for the aircraft rather than its actual, instantaneous position. This has the effect of introducing some lead compensation into the targeting process and reduces transients during the transition to LR. A projection interval of 2 seconds was used in this study.

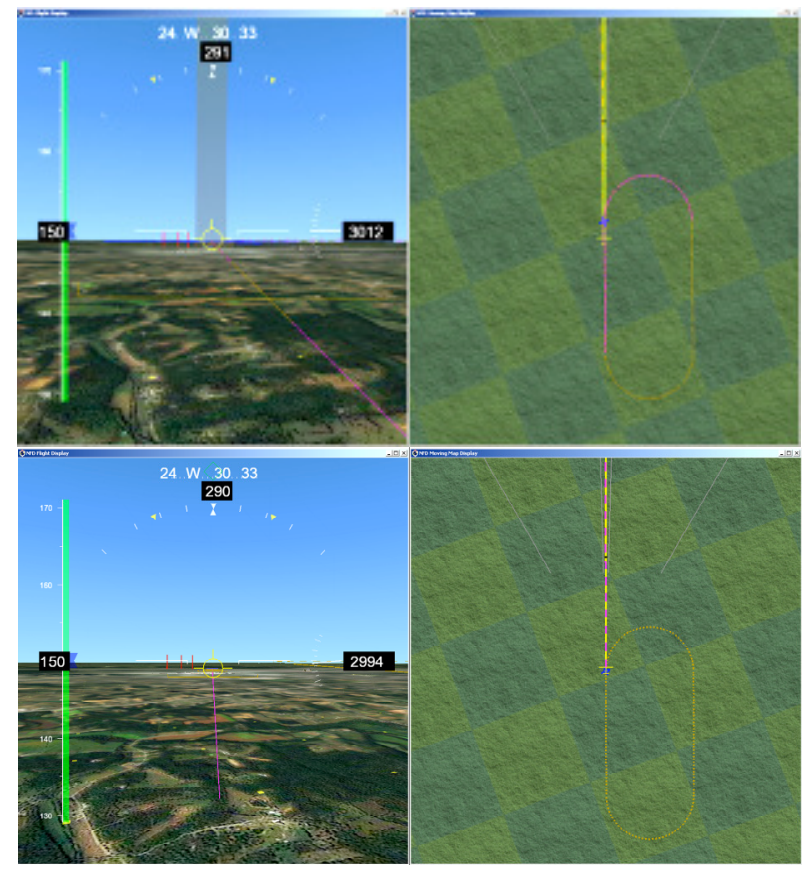

Figure 9. Screen shots showing displays before and after pilot changes sequencing
Airspace procedures often have junctions or two ways of proceeding beyond a decision point. For example, on a precision approach segment a pilot is expected to make the decision to continue the approach to landing or initiate a missed approach at or before reaching the decision altitude (DA). Similarly, from the in-bound leg of a holding pattern, there is the option of staying in the pattern or leaving, usually by joining a leg connecting to the in-bound leg. In these situations, the H-mode allowed the pilot to control the sequencing within LR using stick inputs (i.e., forces) designed to be operationally consistent with manual control. The default sequencing of the path generator was shown on the visual displays via a magenta line extending through the junction indicating what the airplane would do without further direction from the pilot (e.g., upper half of figure 9). Just prior to reaching a junction (6 seconds ahead) the interaction manager issued a sequence of haptic alert signals that felt comparable to highway rumble strips through a car's steering wheel. The rumble strip cue marked the opening of a time window during which the interaction manager was sensitive to a low, but sustained stick input consistent with taking the other path. For example, considering the situation shown in 
figure 9, the default action is to roll into a right turn to remain in the holding pattern. If the pilot resists the automation's input when it attempts to perform this roll or applies a slight force to the left prior to the automation's input, the automation will change its sequencing to following the alternate path. The sequencing force threshold was set slightly below the level of the active stick detent to minimize unintended path disturbances and sequencing. The window remained open until the aircraft was just past the junction ( 1 second beyond). If the sequencing changed, the magenta line rapidly switched to the new path. The pilot could also haptically monitor the stick activity to ensure that the expected path was being followed. If the pilot needed to transition after the window closed, he could accomplish this with a brief transition to TR, perform a manual maneuver to the desired path, and then transition back to LR via a proximity join. This sort of transition involved only a second or two of pilot involvement and the exchange of control was usually very fluid.

At junctions, the automation's default action tended to be the more "conservative" option. For example, at decision height, the default sequencing of the automation was to transition to the missed approach, and once established in a holding pattern the airplane remained in the pattern until the pilot made a positive action to exit. This design strategy was chosen to encourage pilot engagement at key decision points.

\section{Description of the Evaluation}

The purpose of the evaluation was an exploratory assessment of some of the key aspects of the H-mode concept and its overall usability. The evaluation focused on a pilot's ability to efficiently task the automation through the described methods and to assess its ease of use and utility in terminal area operations. Since management of the automation is accomplished primarily by manually flying the airplane to precisely direct its velocity-vector or position relative to a desired pathway, there is a clear potential for its usability to suffer in the presence of turbulence. To assess the presence and severity of this impact, the evaluation was conducted in a motion-based simulator with and without the motion active and with and without simulated turbulence.

The simulation model used in the study was representative of a twin-turboprop commuter aircraft with a wing loading of 58 pounds per square foot. The simulation was hosted in the Visual-

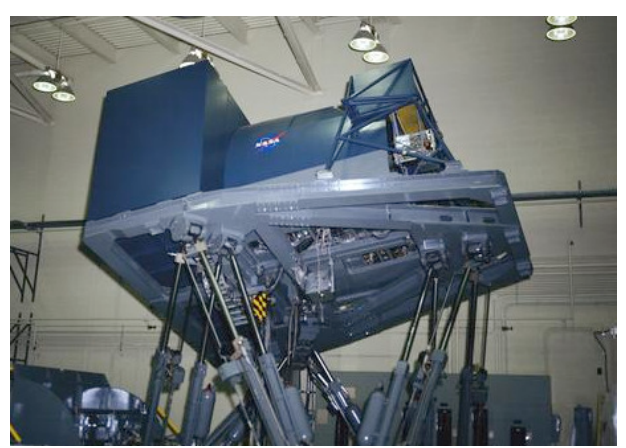

Figure 10. Exterior of the Visual-Motion Simulator Motion Simulator (VMS) at NASA Langley Research Center [18]. Figure 4 provides a photograph of the cockpit as configured during the study while figure 10 shows the motion base and cab housing the cockpit. The majority of the evaluation took place in simulated instrument meteorological conditions (IMC) and the external visual system was not a factor. The exception consisted of several approach tasks involving a ceiling set near DA, requiring subjects to look outside for the runway environment prior to reaching DA. For test conditions involving simulated turbulence, a Dryden spectrum model was used [19]. The root-mean-square intensity of the turbulence was set to the highest level that would not regularly exceed the rate and position limiters of the motion base. Numerically, this intensity was six feet per second, which is considered moderate. Subjectively, using the FAA's turbulence reporting criteria [20], most subjects also rated the turbulence as "moderate". As defined by the FAA's criteria moderate turbulence causes occupants to feel definite strains against the seat belts and dislodges unsecured objects.

To evaluate the ease of tasking the H-mode to perform a desired action and transitioning to LR, the first part of the evaluation involved a series of task elements that individually exercised the functionalities described earlier. These tasks are summarized in table 2 along with the performance criteria used to guide Cooper-Harper pilot ratings (CHR) [21]. The primary data collected during these task elements were time histories including audio and video of the subjects' interaction and their Cooper-Harper ratings and associated comments. The evaluation pilots were allowed to repeat tasks as desired prior to providing a CHR. Given the exploratory nature of the study and the relative immaturity of the $\mathrm{H}$-mode concept, the CHR scale was used primarily as a structured rating tool to facilitate within-subject comparisons across the different test conditions.

Each task element was repeated under three different combinations of simulator motion and turbulence. The first was with the motion active and no turbulence; the second was without motion but with turbulence, and the third was with both motion and turbulence active. The potential fourth condition with no motion or turbulence was evaluated during developmental testing and found not to differ significantly from the case with motion but no turbulence. To allow completion of the test matrix within a single three-hour session, this fourth condition was not included. The condition with turbulence but no motion was of interest for two reasons. The first was to evaluate the effects of 
turbulence-induced motion and vibration on the pilot directly by comparing against the case with the motion active. The second point of interest is that this combination reflects a remotely-piloted, unmanned aircraft system implementation in that the airplane would experience turbulence while the operator presumably would not.

Table 2. Summary of task elements and associated performance criteria

\begin{tabular}{|c|c|c|c|c|c|}
\hline Capability & $\begin{array}{c}\text { Elemental } \\
\text { Task }\end{array}$ & $\begin{array}{c}\text { Initial } \\
\text { Condition }\end{array}$ & End Condition & $\begin{array}{c}\text { Desired } \\
\text { Performance }\end{array}$ & $\begin{array}{c}\text { Acceptable } \\
\text { Performance }\end{array}$ \\
\hline Track hold & $\begin{array}{l}\text { From } 30 \text { degree } \\
\text { bank, roll-out, } \\
\text { capture specified } \\
\text { heading, use track } \\
\text { hold to transition } \\
\text { to LR along } \\
\text { specified heading } \\
\text { and constant } \\
\text { altitude }\end{array}$ & $\begin{array}{l}\text { TR, initial } \\
\text { heading more } \\
45 \text { degrees } \\
\text { from final } \\
\text { heading, } \\
\text { level flight at } \\
\text { desired } \\
\text { altitude }\end{array}$ & $\begin{array}{l}\text { LR coupled to } \\
\text { pathway along } \\
\text { specified track, } \\
\text { constant altitude }\end{array}$ & $\begin{array}{l}\text { Track within } 2 \\
\text { deg of specified, } \\
\text { Altitude within } 50 \\
\mathrm{ft} \text {, no more than } 2 \\
\text { trigger pulls used } \\
\text { to achieve } \\
\text { condition }\end{array}$ & $\begin{array}{l}\text { Track within } 3 \\
\text { deg of specified, } \\
\text { Altitude within } \\
100 \mathrm{ft} \text {, no more } \\
\text { than } 2 \text { trigger } \\
\text { pulls used to } \\
\text { achieve condition }\end{array}$ \\
\hline Point to Program & $\begin{array}{l}\text { From } 30 \text { degree } \\
\text { bank, roll-out, } \\
\text { target waypoint } \\
\text { and } \mathrm{P} 2 \mathrm{P} \text { to } \\
\text { generate pathway } \\
\text { coupled to } \\
\text { waypoint and } \\
\text { transition to LR }\end{array}$ & $\begin{array}{l}\text { TR, initial } \\
\text { heading more } \\
\text { than } 40 \\
\text { degrees from } \\
\text { waypole, } \\
\text { level flight }\end{array}$ & $\begin{array}{l}\text { LR coupled to } \\
\text { pathway leading } \\
\text { to waypoint }\end{array}$ & $\begin{array}{l}\text { Task completed } \\
\text { correctly in }<20 \\
\text { seconds, no more } \\
\text { than } 2 \text { trigger } \\
\text { pulls }\end{array}$ & $\begin{array}{l}\text { Task completed } \\
\text { correctly in }<20 \\
\text { seconds, no more } \\
\text { than } 3 \text { trigger } \\
\text { pulls }\end{array}$ \\
\hline $\begin{array}{l}\text { Deconfliction } \\
\text { (i.e., Point to Program with } \\
\text { multiple valid options) }\end{array}$ & $\begin{array}{l}\text { Pilot to transition } \\
\text { to correct LR } \\
\text { behavior from } 3 \\
\text { choices in the } \\
\text { targeting criteria }\end{array}$ & $\begin{array}{l}\text { TR with two } \\
\text { path segments } \\
\text { and } 1 \\
\text { waypoint } \\
\text { within the } \\
\text { targeting } \\
\text { criteria }\end{array}$ & $\begin{array}{l}\text { LR coupled to } \\
\text { the specified } \\
\text { segment of } \\
\text { waypoint }\end{array}$ & $\begin{array}{l}\text { No more than } 2 \\
\text { trigger pulls to } \\
\text { select the correct } \\
\text { feature }\end{array}$ & $\begin{array}{l}\text { No more than } 3 \\
\text { trigger pulls to } \\
\text { select the correct } \\
\text { feature }\end{array}$ \\
\hline Proximity Join & $\begin{array}{l}\text { From straight and } \\
\text { level flight, } \\
\text { maneuver onto } \\
\text { curved segment } \\
\text { and proximity join }\end{array}$ & $\begin{array}{l}\text { TR, straight } \\
\text { and level, co- } \\
\text { altitude with } \\
\text { curving } \\
\text { segment }\end{array}$ & $\begin{array}{l}\text { LR coupled to } \\
\text { curved segment }\end{array}$ & $\begin{array}{l}\text { No more than } 2 \\
\text { trigger pulls and } \\
\text { without } \\
\text { subjectively } \\
\text { objectionable } \\
\text { transients }\end{array}$ & $\begin{array}{l}\text { No more than } 3 \\
\text { trigger pulls }\end{array}$ \\
\hline Junction, horizontal & $\begin{array}{l}\text { From inbound leg } \\
\text { of holding pattern, } \\
\text { sequence } \\
\text { automation to exit } \\
\text { the hold }\end{array}$ & $\begin{array}{l}\text { LR on } \\
\text { inbound leg } \\
\text { of holding } \\
\text { pattern }\end{array}$ & $\begin{array}{l}\text { LR coupled to } \\
\text { segment leaving } \\
\text { holding pattern } \\
\text { (e.g., figure 9) }\end{array}$ & $\begin{array}{l}\text { Smooth transition } \\
\text { completely in LR. } \\
\text { Clear awareness } \\
\text { of transition }\end{array}$ & $\begin{array}{l}\text { Transition to TR } \\
\text { used to get on } \\
\text { new path but } \\
\text { subjectively } \\
\text { always in control }\end{array}$ \\
\hline Junction, vertical & $\begin{array}{l}\text { By DA of final } \\
\text { approach segment, } \\
\text { sequence } \\
\text { automation to } \\
\text { complete landing }\end{array}$ & $\begin{array}{l}\text { LR inbound } \\
\text { on final } \\
\text { approach, } 30 \\
\text { seconds from } \\
\text { DA }\end{array}$ & $\begin{array}{l}\text { LR below DA } \\
\text { coupled to } \\
\text { landing segment }\end{array}$ & $\begin{array}{l}\text { Smooth transition } \\
\text { completely in LR. } \\
\text { Clear subjective } \\
\text { awareness of } \\
\text { transition }\end{array}$ & $\begin{array}{l}\text { Transition to TR } \\
\text { used to get on } \\
\text { new path but } \\
\text { subjectively } \\
\text { always in control }\end{array}$ \\
\hline
\end{tabular}

The second part of the evaluation assessed the overall operational utility and ease of use of the concept. Subjects performed terminal area arrivals and instrument approaches using the H-mode at their discretion. The simulated terminal area is shown in figure 11 and is based on the Louisville International Airport (KSDF) with area navigation (RNAV) approach procedures to runways 35L, 35R, and 29. Subjects had access to a paper copy of the chart shown in figure 11 to augment the cockpit displays.

Each subject flew two arrival scenarios and each scenario lasted approximately 8 minutes. Both scenarios were performed with the motion base active. The first scenario was performed without turbulence while the second scenario included turbulence. The primary data collected during these operational scenarios were time histories including audio and video of the subjects interaction; the subjects subjective ratings of workload (assessed via the NASA Task Load Index (TLX)) [22] and situation awareness (assessed via the Situation Awareness Rating 


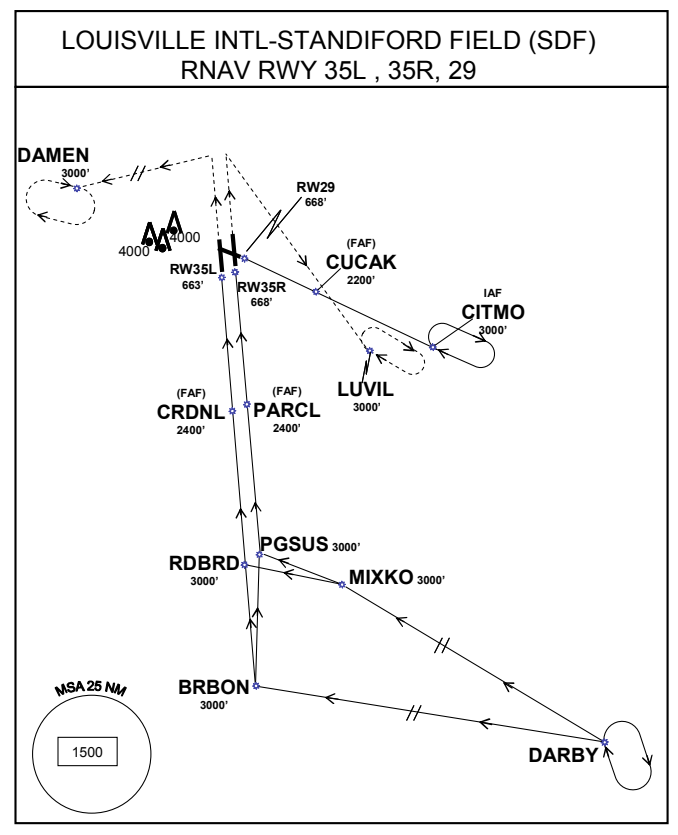

Figure 11. Terminal area

Technique(SART)) [23]; and an exit questionnaire and interview performed immediately after the simulation session.

The initial condition for the first scenario positioned the aircraft midway between CITMO and MIXKO at 4000'. The first element of the clearance was to hold at 4000' at CITMO as published. Once established in the hold at 4000', subjects were instructed to descend in the hold to 3000' and initiate the approach to runway 29 from CITMO. Between CITMO and CUCAK, the clearance was updated to reflect the closure of runway of runway 29. Subjects were instructed to maintain $3000^{\prime}$, a track of 180 degrees and to expect a clearance to runway 35L. Once the airplane was abeam CRDNL, subjects were cleared via CRDNL to conduct the approach to $35 \mathrm{~L}$. The height of the ceiling for this scenario was set below DA and subjects were expected to execute a missed approach at the DA. The run ended after subjects were stabilized on the missed approach.

In the second scenario, the initial position was west of RDBRD at 3000' and subjects were cleared to join the approach to $35 \mathrm{~L}$ at RDBRD. Between RDBRD and CRNDL subjects were told they were overtaking slower traffic and offered a go-around or transition to 35R (all subjects transitioned). Prior to reaching PARCL, runway $35 \mathrm{R}$ closed and subjects were cleared to CUCAK to fly the approach to runway 29 . The ceiling for the second scenario was just above minimums (20' above) and subjects were expected to continue the approach below DA. The runs ended after the subjects were stabilized on the approach path below DA.

The evaluation subjects were 5 general aviation pilots with a range of experience. Three of the subjects held instrument ratings although only 2 were current. One subject was an active private pilot without an instrument rating. The final subject was a student pilot who had performed local solo flights. The subjects also had a wide range of experience with general aviation autopilot systems, from no exposure through state-of-art systems on current production aircraft such as the Cirrus SR-22. All the evaluation pilots had engineering backgrounds and were familiar with the development and evaluation of advanced flight system concepts in simulation and the use of the subjective ratings tools.

Prior to the data collection session in the VMS, all subjects participated in individual training sessions. Each session consisted of an overview of the high-level goals of the study followed by an overview of the basic simulation environment including the aircraft model, the basic displays and controls, and the airspace procedures. Subjects then practiced in a fixed-based simulator equipped with the same active stick and displays as used in the VMS. After the subjects demonstrated an acceptable level of proficiency and personal comfort manually flying the airplane and procedures, they were given a briefing on the functional capabilities of the H-mode. This briefing was combined with hands-on demonstration and practice in the fixed-base simulator. Again, subjects were allowed to practice until they demonstrated an acceptable level proficiency and personal comfort. The complete training session required less than three hours and the portion allocated to the H-mode required less than one hour. The data collection session in the VMS occurred within a few of days of the training session. The VMS sessions started with a few minutes free maneuvering to become familiar with the cockpit, the additional motion cues, and the effects of turbulence. Once subjects were comfortable with the VMS environment, the test matrix was started. The data collection sessions lasted 3 hours including a brief break between the completion of the task elements and start of the operational scenarios.

\section{Results and Discussion}

\section{A. Elemental Tasks}

Figure 12 presents the Cooper-Harper Ratings given by the five evaluation pilots for the six elemental tasks and the three combinations of motion and turbulence. Without turbulence all of the tasks resulted in level-1 ratings by a majority of the evaluation pilots, indicating that desired performance could generally be achieved with no worse than some mild deficiencies requiring minimal compensation. Deficiencies called out in the comments included 
Track Hold Task
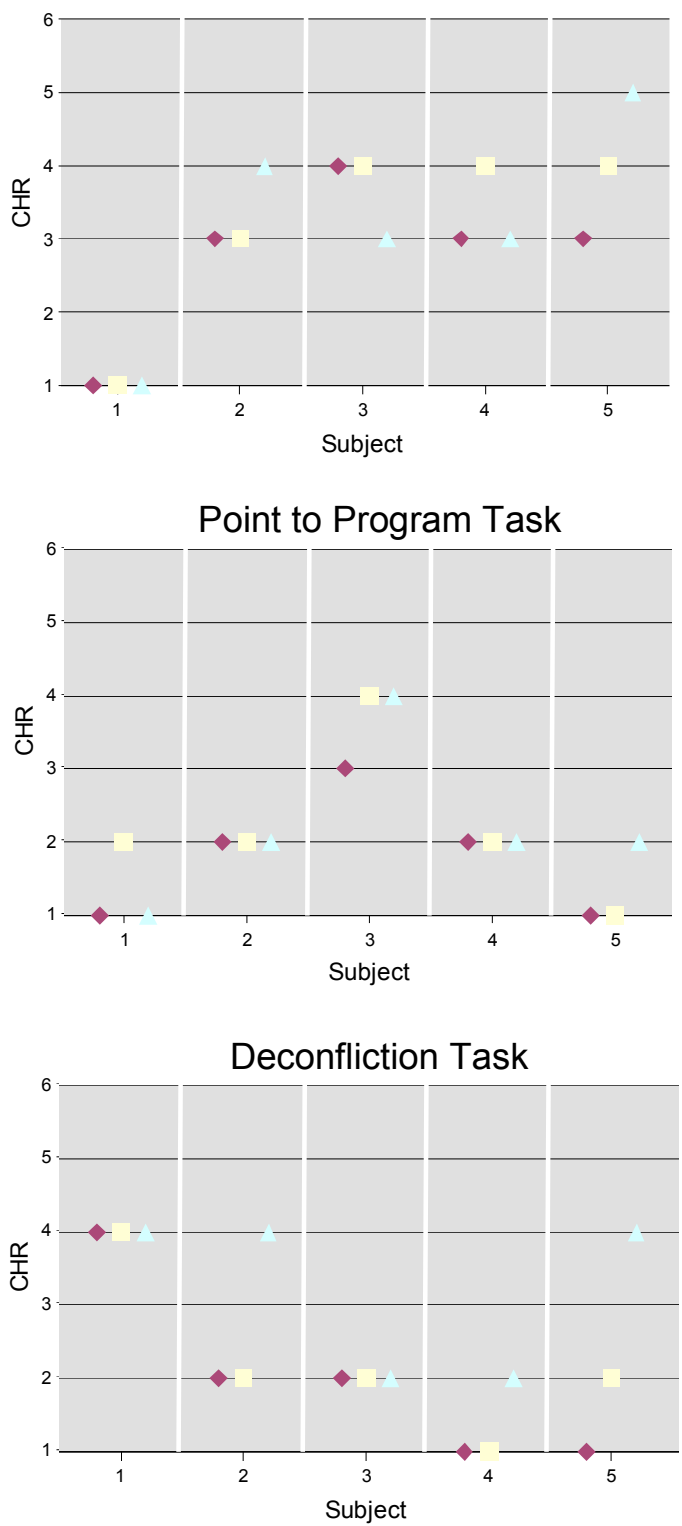
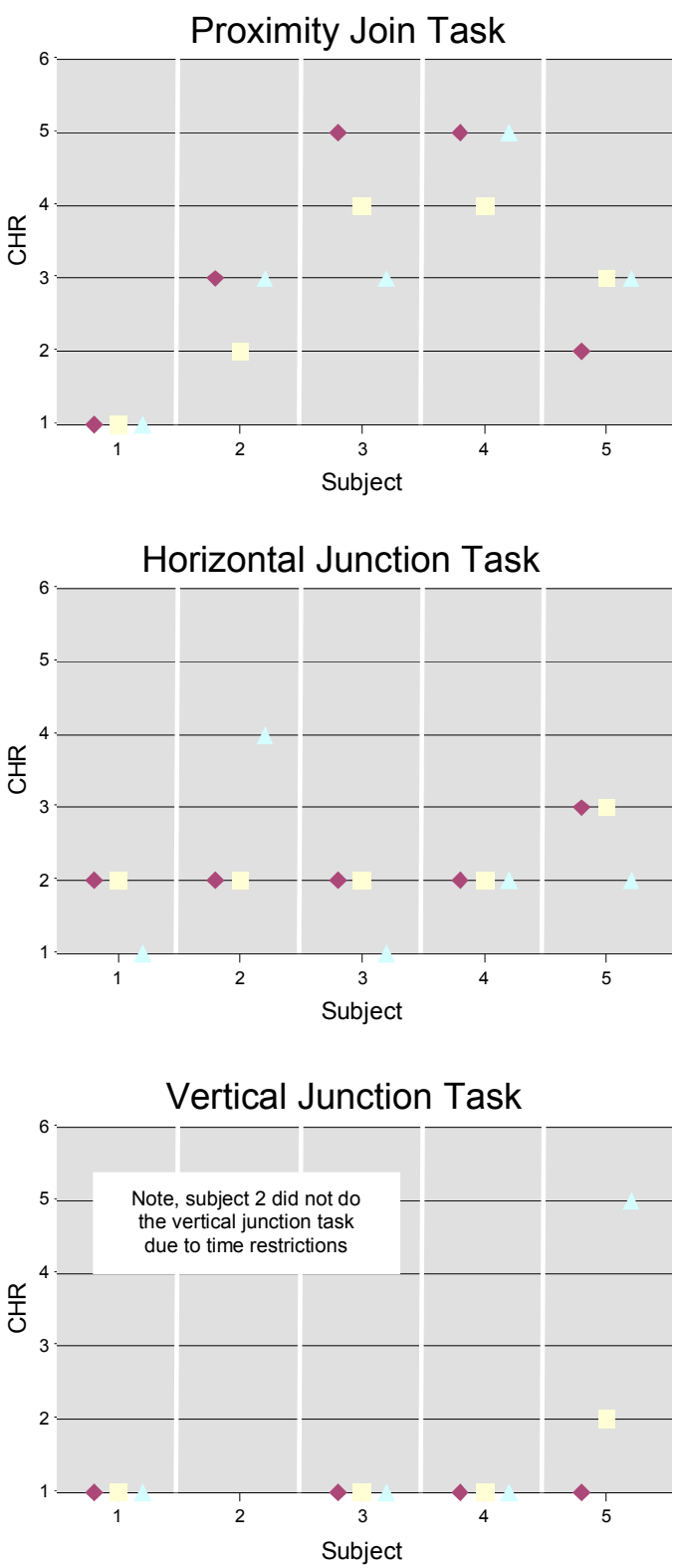

\section{Figure 12. Cooper-Harper ratings for the elemental tasks}

With motion, no turbulence No motion, with turbulence With motion and turbulence

several items in the basic display symbology. These included a compressed heading scale on the PFD that made capturing a desired heading more difficult and the lack of an explicit "horizon line" on the PFD. The natural divide between the blue sky and the synthetic terrain presentation provided a horizon on the PFD, but the "far clipping plane" of the graphics rending process resulted in this horizon being 18 miles in front of the aircraft rather than infinitely ahead. As a consequence, commanding level flight required placing the FPM somewhat above rather than on the apparent horizon. These two items primarily impacted the track hold task by increasing the workload of both maintaining constant altitude and capturing the specified heading. For the other tasks, symbology elements specific to the H-mode were the primary references. For the H-mode related symbology, a software issue caused inconsistent highlighting of one of the external features during the de-confliction task and pilots had to rely on their memory to infer when it was highlighted. This issue increased the mental workload of the task and is responsible for subject 1's level-2 rating even without turbulence present. Without turbulence, the proximity join task involving maneuvering 
onto a curved segment was rated level 2 by two subjects. Both subjects had difficulty establishing a steady closure rate toward the curved segment and experienced instances where the path highlighting indicated that coupling was possible, only to have moved out of the criteria by the time the trigger was pulled and registered by the software. With no feature recognized as admissible when the system registered a trigger pull, the automation transitioned to LR via a track hold rather than the expected proximity join. The subjects would quickly detect the unintended behavior due to stick force changes (i.e., the automation tried to roll wings level), and the fading-in of the automation's stick commands allowed them to transition back to TR before significant path transients occurred. Not surprisingly, the subjects found the occurrences frustrating and lowered their ratings accordingly.

Exposing the aircraft model to simulated turbulence but not the cockpit environment (i.e., motion-base off) resulted in limited changes to the subject's CHR, perhaps within the variability of within-subject ratings. While the

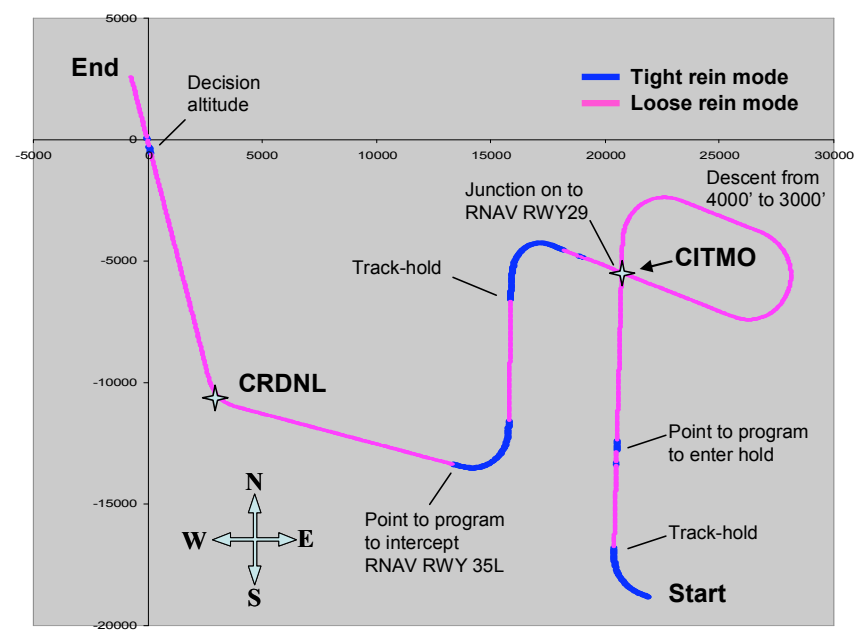

Figure 13. Planform view showing mode useage during first operational scenario

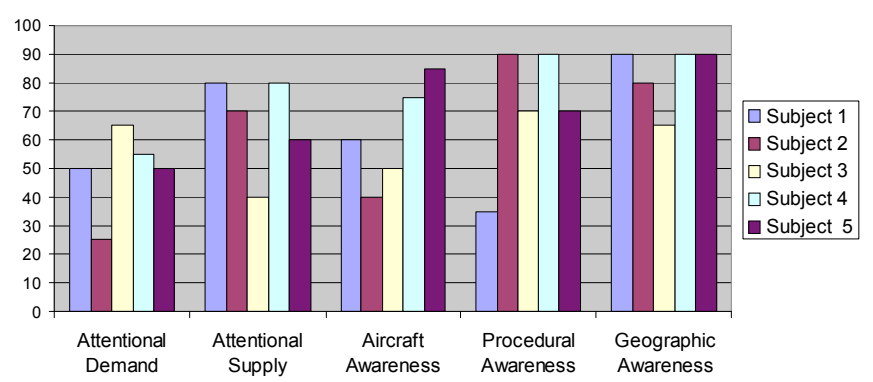

Figure 14. SART ratings for the operational scenarios

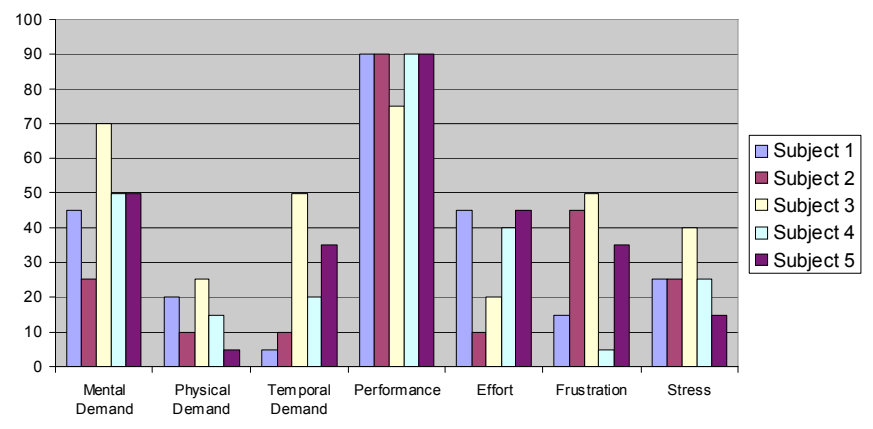

Figure 15. TLX ratings for the operational scenarios limited size and design of this preliminarily evaluation (e.g., potential learning and ordering effects) limit the ability to make any definitive statements, the magnitude of any turbulence related impacts appears to be small. The runs with both the turbulence and motion active created a fairly adverse cockpit environment but also had limited impact on pilot ratings. The ratings from most subjects and tasks were within a one point of their other ratings, although larger decrements were observed and highlight areas needing refinement. One subject in particular (\#5) consistently reported increased difficulty reading the displays and discerning the haptic cues with the cockpit shaking. In the junction tasks, two subjects (2 and 5) gave level II ratings due to uncertainty as to whether the automation had sequenced to the desired path. In these instances, the pilots promptly reverted to TR and proximity joined on the desired outbound path.

\section{B. Operational Scenarios}

The five subjects completed the two scenarios without significant difficulty or errors, using the capabilities of the $\mathrm{H}$-mode as expected and with no significant changes in usage between conditions with and without turbulence. The subjects typically transitioned to LR whenever possible and used TR as needed to transition between LR behaviors. For the two scenarios used in this evaluation, on average the subjects used LR $81 \%$ of the time and TR $19 \%$. Figure 13 shows the mode usage for the first scenario as performed by subject 1 . In addition to the expected TR maneuvers to transition between different LR behaviors, close examination of figure 13 shows several very brief transitions to TR and back to LR. These transitions were typically used to verify the active LR behavior.

The subjects' ratings for situation awareness and workload are presented in figures 14 and 15 respectively. One set of ratings was collected after both scenarios had been completed with the exit questionnaire serving as the primary means of capturing subjective impressions of the effects of turbulence. In keeping with the design objectives of the H-mode, the subjects generally self-reported as operating with a moderate level of effort, i.e., neither 
under nor overworked. The subjects also considered themselves reasonably aware of the situation and feeling as though they had spare mental and physical capacity. The subjects were also generally satisfied with their performance as indicated by ratings in the upper quarter of the scale.

Several subjects' SART rating relative to the status of the airplane (and the automation) and TLX "frustration" rating were negatively influenced by an unintentional implementation detail. After a procedure had been selected via a $\mathrm{P} 2 \mathrm{P}$ transition, its highlighting was turned off and its appearance became identical to an unselected path. The intention was that the visual depiction of the H-path would indicate which path had been selected. However in some situations, the H-path did not initially extend all the way to the selected feature making the selection unobservable after the transition to LR until the airplane had traveled some distance. The implementation has since been changed so that a selected pathway remains highlighted until the H-path reaches it.

Another concern was the occurrence of an unintended sequencing to land by one of the subjects (\#3) during scenario 1 . The subject did not recall intentionally sequencing the automation to continue descent below the DA and was surprised when it did not automatically initiate a missed approach at DA. However, because her hand was already on the stick monitoring the automations actions, she promptly transitioned to TR and manually initiated the missed as the airplane reached DA. The occurrence resulted in increased ratings for mental and temporal demand as well as frustration.

\section{Questionnaires and interviews}

The subjects completed questionnaires following the training session in the fixed base simulation and the data collection session in the motion-base simulator. The questionnaires used a combination of five-level Likert items (e.g., statements to which the subject expresses agreement or disagreement using five ordered response levels) and free response questions. While completing the questionnaires, the subjects were also encouraged to verbally expound on their written responses. The questionnaires focused on understanding the subjects' perceptions of the overall utility of the H-mode; its ease of use and learnability; specific design details such as the haptic cues and visual symbology. The questionnaire that followed the second session also tried to draw out any changes in the subjects' perceptions between the two sessions and between conditions with and without motion and turbulence.

Overall, the majority of subjects (3) agreed strongly with the statement that the H-mode could provide a useful complement or alternative to conventional interfaces. The remaining two subjects provided neutral responses and in their comments expressed concern regarding the use of particular features (e.g., the haptic cues) during enroute operations with longer length legs. Their written comments were supportive of the concept for the terminal area operations as evaluated in the study. In response to the statement, "the presence of turbulence and motion reduced the usability of the H-mode", four subjects responded "not or all" or "slightly" while one subject (\#5) indicated a "moderate decline". This rating is consistent with the fifth sujbect's difficulty reading the displays and discerning the haptic cues with turbulence and motion active. In response to the question, "overall, learning to use the H-mode is?", all the subjects indicated that it was either easy or very easy.

Between the two sessions there seemed to be an interesting shift in the general acceptance of the haptic status cues. Several subjects commented that the haptic status cues seemed unnecessary or even annoying in the fixedbase training session only to comment favorably after the session in the motion-based simulator. With turbulence and motion active, the visual displays inevitably become harder to read and the complementary haptic status information probably helps to offset this effect. In this study, the amplitudes of the haptic cues were constant and something of a compromise between being too prominent without motion and being difficult to detect with it. It is likely that adjusting the amplitudes to maintain constant signal strength relative to background measurements (e.g., low in smooth air and stronger in turbulence) would increase their effectiveness and acceptance. Anecdotally, based on this evaluation and many less formal demonstrations, there seems to be a clear bi-modal distribution of people having an initial like or dislike for the haptic cues. However, after modest exposure most people warm to the concept and after extended exposure, many people note its absence as a lifeless sensation.

\section{Summary and future work}

The subjects found the H-mode generally straightforward to learn and use. Even the subjects having no or minimal prior experience with autopilot or flight management systems were able to effectively use the capabilities evaluated in this study to perform representative instrument arrivals and approaches in challenging conditions after receiving approximately an hour of training specifically on the system.

Although the Cooper-Harper ratings deteriorated slightly with the introduction of turbulence and turbulence induced cockpit motion the subjects' comments on the concepts overall benefit and usability generally became more favorable after using it with turbulence and motion. A contributor to this improvement is probably the basic auto- 
flight functions being appreciated more in the unsettled conditions. Since these functions are independent of the interface system (e.g., commanding procedural coupling via keypad versus point to program) future experiments will formally investigate the affects of the H-mode interface on human-automation system performance compared to conventional baselines such as a mode control panel and FMS control-display unit.

While the overall usability of the concept was demonstrated in this study, the results also indicate several areas where improvement is warranted. The study uncovered several situations in which the state of the automation was unclear or indiscernible without additional observation or inputs. Most of these deficiencies can (and have been) remedied through minor modifications to the software making any active path selection clearly discernable. In addition, we have made minor refinements to some of the visual display elements (e.g., increased line widths) that enhance readability in the presence of adverse motion. More fundamental concerns were observed in the current implementation pertaining to uncertain or inadvertent sequencing of the automation through junctions (e.g., at decision height) and inadvertent generation of track-hold trajectories when the criteria for commanding a path-based behavior (i.e., P2P or proximity join) are exited just prior to an attempted engagement. Several strategies are being investigated to resolve these issues while retaining the simplicity of the human-machine interaction and its similarity to manual flying.

Continued development of the fundamental H-mode concept includes integrating in useful dynamic behaviors such as conflict avoidance using applicable flight rules (e.g., VFR and emerging Next-Generation airspace concepts) and station keeping or formation flying relative to other aircraft. Additionally, integrating in richer sources of realtime information such as machine vision (e.g., optical and multi-spectral feature recognition) is of interest. Ideally, the system should autonomously augment its on-board data bases with real-time perceptions (both external and internal) as needed to conduct basic flight maneuvers with precision and safety comparable to or exceeding a human pilot. At this point, pilot or operator training could focus less on basic stick and rudder skills and more on the judgment and decision making essential to effective flight operations and which are far more difficult to reliably automate. Our long-term goals include significantly reducing the initial and recurrent training required to safely conduct near-all-weather flight operations; increasing the safety and mission capabilities of single-pilot operations to levels comparable to multi-pilot operations; and enabling optionally piloted vehicles that support flexible, dynamic direction by operators with expertise in the application domain rather than aviation (e.g., experts in wildlife research, fire fighting, or law enforcement rather than piloting).

\section{References}

${ }^{1}$ Billings, Charles, 1997, Aviation Automation: The Search for a Human-Centered Approach. Mahwah, NJ: Lawrence Erlbaum Associates.

${ }^{2}$ FAA Human Factors Team, 1996, "The Interfaces between Flightcrews and Modern Flight Deck Systems," Washington D. C., FAA.

${ }^{3}$ Wiener Earl, 1998, “Cockpit Automation,” In E. L. Wiener \& D. C. Nagel (Eds.), Human Factors In Aviation, San Diego, CA: Academic Press, pp. 433-461.

${ }^{4}$ Sherry, Lance, Peter Polson; Michael Feary, 2001, "Designing User-Interfaces for the Cockpit: Five Common Design Errors and how to Avoid Them," Society of Automotive Engineers, 02WAC-98, Warrendale, PA.

${ }^{5}$ Steering Committee for the Decadal Survey of Civil Aeronautics, 2006, "Decadal Survey of Civil Aeronautics: Foundation for the Future," Washington, D. C., The National Academies Press.

${ }^{6}$ Williams, Kevin, 2004, “A Summary of Unmanned Aircraft Accident/Incident Data: Human 6A3-13 Factors Implications", Oklahoma City, OK, Civil Aerospace Medical Institute, FAA.

${ }^{7}$ Minsky, Marvin; Push Singh; Aaron Sloman, 2004, “The St. Thomas Common Sense Symposium: Designing Architectures for Human-Level Intelligence,” AI Magazine, summer 2004, Menlo Park, CA, AAAI Press.

${ }^{8}$ Flemisch, F. O., Adams, C. A., Conway, S. R., Goodrich, K. H., Palmer, M. T., \& Schutte, P. C. (2003). The H-Metaphor as a guideline for vehicle automation and interaction. (Technical Memorandum No. NASA/TM-2003-212672). Hampton, VA: NASA Langley Research Center.

${ }^{9}$ Goodrich, K. H., Williams, Schutte, Flemisch, 2006, "Application of the H-Mode, a Design and Interaction Concept for Highly Automated Vehicles, to Aircraft", IEEE 1-4244-0378-2/06/

${ }^{10}$ Schutte, P. C., Goodrich, K. H., et al, 2007, “The Naturalistic Flight Deck System: An Integrated System Concept for Improved Single-Pilot Operations", (Technical Memorandum No. NASA/TM-2007-215090). Hampton, VA: NASA Langley Research Center.

${ }^{11}$ Donald A. Norman, 2007, The Design of Future Things. Basic Books, ISBN-13: 978-0465002276

12 Robert W. Miller, 2001, Western Horse Behavior and Training. New York, NY: Doubleday.

${ }^{13}$ GNEF, German National Equestrian Federation (2002). The Principles of Driving.

Buckingham; UK: Kenilworth Press. 
${ }^{14}$ Quigley, Morgan, Goodrich, Michael A., Beard, Randal W., 2004 , "Semi-Autonomous Human-UAV Interfaces for FixedWing Mini-UAVs", Proceedings of 2004 IEEE International Conference on Intelligent Robots and Systems, September 28 October 2,2004, Sendai, Japan

${ }^{15}$ Kelly S. Hale and Kay M. Stanney, 2004 "Deriving Haptic Design Guidelines from Human Physiological, Psychophysical, and Neurological Foundations", IEEE Computer Graphics and Applications, March/April 2004

${ }^{16}$ Flemisch, Frank; Ken Goodrich, Shelia Conway, 2005, "ITS at the crossroads of manually controlled and automated transport: The H-Metaphor and its first applications (progress update 2005)," Hannover Germany, Presented at The 5th European Congress and Exhibition on Intelligent Transport Systems and Services HIT.

${ }^{17}$ Flemisch, Frank, J. Kelsch, A. Schieben, J. Schindler, 2006, "Stücke des Puzzles hochautomatisiertes Fahren: H-Metapher und HMode“, Workshop Fahrerassistenzsysteme; Löwenstein, Germany.

18 Parrish, R.V., Dieudonne, J. E..; and Martin, D. J., 1973 "Motion Software for a Synergistic Six-Degree-of-Freedom Motion Base. NASA TN D-7350, 1973.

19 Department of Defense, December 1997 ,Department of Defense, Flying Qualities of Piloted Aircraft, MIL-HDBK-1797

${ }^{20}$ Federal Aviation Administration, February 2008, “Aeronautical Information Manual. Official Guide to Basic Flight Information and ATC Procedures, Federal Aviation Administration, Washington, DC

${ }^{21}$ Cooper, G.E., and Harper, R.P. Jr., April 1969, "Use of Pilot Rating in the Evaluation of Aircraft Handling Qualities," NASA TN D-5153.

${ }^{22}$ Hart S. G., Lowell S. E., 1988, "Development of NASA-TLX (Task Load Index): Results of Empirical and Theoretical Research.” Human Mental Workload (pp 239-250), North Holland Press, Amsterdam.

${ }^{23}$ Taylor, R. M., 1989. "Situational awareness rating technique (SART): The development of a tool for aircrew systems design." Proceedings of the AGARD AMP Symposium on Situational Awareness in Aerospace Operations, CP478. Seuilly-sur Seine: NATO AGARD. 